\title{
Strong Electronic and Counterion Effects on Geminal Digold Formation and Reactivity as Revealed by Gold(I)-Aryl Model Complexes**
}

\author{
Dieter Weber, T. David Jones, Laura L. Adduci, and Michel R. Gagné \\ Department of Chemistry, University of North Carolina at Chapel Hill, Chapel Hill, NC 27516-3290 \\ (USA)
}

Michel R. Gagné: mgagne@unc.edu

\section{Keywords}

aurophilicity; geminal diauration; gold complexes; protodemetalation

Gold(I) cations have emerged as efficient and often times uniquely effective catalysts for the formation of $\mathrm{C}-\mathrm{X}(\mathrm{X}=\mathrm{C}, \mathrm{O}, \mathrm{N})$ bonds. ${ }^{[1]}$ Its use as a soft $\pi$-acid for the activation of $\mathrm{C}-\mathrm{C}$ multiple bonds has led to proposed intermediates that include $\pi$-gold, Au-vinyl, Au-alkyl, and $\mathrm{Au}-$ carbene structures. ${ }^{[2]}$ In many instances a transient $\mathrm{Au}-\mathrm{C} \sigma$-bond is converted into a $\mathrm{C}-\mathrm{E}$ bond through its reaction with an $\mathrm{E}^{+}$electrophile. ${ }^{[3]}$ Recently, we provided evidence that the intramolecular hydroarylation of allenes proceeded through two different gold-vinyl intermediates, one mononuclear (A), and one dinuclear (B), with the latter acting as the catalyst's resting state. The digold structure was proposed to result from the reaction of $\mathrm{LAu}^{+}$with monogold-vinyl A [Eq. (1)]. ${ }^{[4]}$
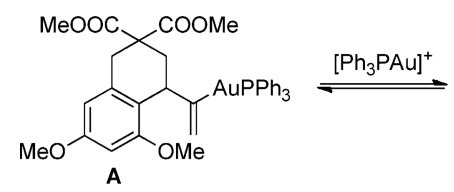

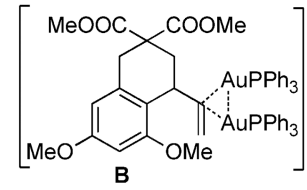

The proposal that the digold resting state $\mathbf{B}$ contained a $\mathrm{Au}_{2} \mathrm{C}$ three-center-two-electron bond, which was additionally stabilized by an aurophilic closed shell interaction of significant strength $\left(5-10 \mathrm{kcal} \mathrm{mol}^{-1}\right),{ }^{[5]}$ was based on the aromatic digold compounds reported by Schmidbaur, Grandberg, and Nesmeyanov and confirmed by recent digold vinyl complexes from Fürstner et al. (Scheme 1). ${ }^{[6]}$ With the exception of above mentioned studies little is known about digold intermediates in gold catalysis. Grandberg, Nesmeyanov, and Schmidbaur have reported their synthesis and structure, but their properties in catalytic applications has yet to be articulated. Since digold formation consumes an otherwise catalytically active $\{\mathrm{LAu}\}^{+}$unit and the digold intermediate was shown to be less reactive

\footnotetext{
***We thank Dr. Peter White and LLA for assistance with crystallography (pwhite@unc.edu and ladduci@unc.edu for correspondence). The Fulbright Foreign Student Fulbright Program (for D.W.) is gratefully acknowledged as is the National Institute for General Medical Sciences (GM-60578).

(C) 2012 Wiley-VCH Verlag GmbH \& Co. KGaA, Weinheim

Correspondence to: Michel R. Gagné, mgagne@unc. edu.

Supporting information for this article is available on the WWW under http://dx.doi.org/10.1002/anie.201107659.
} 
towards $\mathrm{H}^{+}$, one might reasonably surmise that digold formation is inhibitory to catalysis. ${ }^{[7]}$ These considerations prompted studies to experimentally delineate and quantify those factors influencing digold formation. As Fürstner et al. noted, the availability of stable digold vinyl complexes with a $\mathrm{Au}_{2} \mathrm{C}$ three-center-two-electron bond is limited due to their tendency to decompose through a homocoupling pathway. ${ }^{[8]}$ To bypass this situation we instead turned to readily available and easily modifiable aryl complexes as models for catalytically relevant vinyl complexes. This approach has enabled us to determine the affinity of $\left\{\mathrm{R}_{3} \mathrm{PAu}\right\}^{+}$to $\mathrm{R}_{3} \mathrm{PAu}$-aryl compounds and to explore the influence of counterions and Brønsted acids on this equilibrium. These results provide a framework from which to predict and rationalize the equivalent reactivity of gold-vinyl intermediates in catalysis.

$\mathrm{Ph}_{3} \mathrm{PAu}$-aryl complexes (1) were synthesized from $\left[\mathrm{Ph}_{3} \mathrm{PAuCl}\right]$ and the corresponding Grignard reagents, and were found to crystallize either in a monomeric form or with an unsupported $\mathrm{Au}-\mathrm{Au}$ interaction that pairs the compounds. ${ }^{[9-12]}$ Solutions of these compounds were stable to decomposition in $\mathrm{CD}_{2} \mathrm{Cl}_{2}$ over a minimum of $12 \mathrm{~h}$.

The digold(I)-aryl complexes were available through a slight variation of the GrandbergNesmeyanov synthesis of geminally diaurated ferrocenyl complexes (Scheme 1). ${ }^{[6,10]}$ Addition of diethyl ether to a $0.8: 1$ solid mixture of $\left[\mathrm{Ph}_{3} \mathrm{PAuNTf}_{2}\right](\mathbf{3 a})^{[13]}$ and $\left[\mathrm{Ph}_{3} \mathrm{PAuAr}\right]$ at $-78{ }^{\circ} \mathrm{C}$ led to precipitation of the desired $\left[\left(\mathrm{Ph}_{3} \mathrm{PAu}\right)_{2} \mathrm{Ar}^{+}\right]\left[\mathrm{NTf}_{2}{ }^{-}\right]$salt [Eq. (2)]. This procedure could be applied to the synthesis of a variety of gold aryl complexes. In two cases single crystals of sufficient quality for X-ray analysis were obtained to confirm atom connectivity, though twinning and disorder did not allow an analysis of metrical parameters. ${ }^{[14]}$ In general, digold compounds were stable in their precipitated state but decomposed slowly in $\mathrm{CD}_{2} \mathrm{Cl}_{2}$ solution. ${ }^{[6 \mathrm{a}, 8]}$ Alternatively digold-aryl complexes could also be generated by the addition of $\mathbf{3 a}$ to a solution of monogold $\mathbf{1}$.

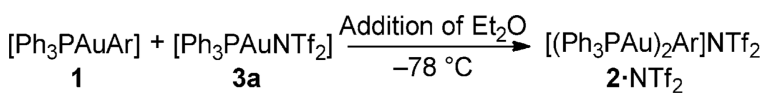

1 equivalent of $\mathbf{3 a}$ was shown to fully convert [(4-MeO- $\left.\left.\mathrm{C}_{6} \mathrm{H}_{4}\right) \mathrm{AuPPh}_{3}\right](\mathbf{1 a})$ to [(4-MeO$\left.\left.\mathrm{C}_{6} \mathrm{H}_{4}\right)\left(\mathrm{AuPPh}_{3}\right)_{2}\right] \mathrm{NTf}_{2}\left(\mathbf{2} \mathbf{a} \cdot \mathrm{NTf}_{2}\right)$. This transformation caused the aromatic and $\mathrm{OMe}$ resonances of the 4-anisyl fragment to shift downfield in the ${ }^{1} \mathrm{H}$ NMR spectrum.

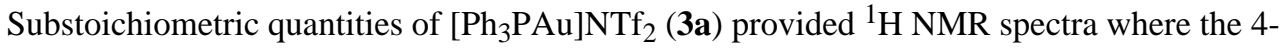
anisyl fragment was time averaged and located between the signals of pure 1a and $\mathbf{2 a} \cdot \mathrm{NTf}_{2}$. Since Grandberg and Nesmeyanov previously observed $\left\{\mathrm{Ph}_{3} \mathrm{PAu}\right\}^{+}$exchange with $\mathrm{Au}-$ ferrocenyl complexes (Scheme 1), we surmised a similar exchange was occurring to average gold-aryl, gold-cation, and digold spectra. ${ }^{[15]}$ Evidence for fast exchange was provided by ${ }^{1} \mathrm{H}$ NMR characterization of solutions obtained from the titration of 3a into $\mathbf{1 a}$. Incremental additions caused a steady downfield shifting of the 4-anisyl resonances until one equivalent of $\mathbf{3 a}$ had been added, at which point the chemical shift matched pure 2a.NTf 2 (Figure 1). More than one equivalent of 3a had no further effect on the chemical shift, suggesting that the equilibrium in Figure 1 strongly favored digold and that no trigold species were formed. ${ }^{[16]}$

Averaged signals and a linear dependence of chemical shift on added 3a were also observed for $\left[\mathrm{PhAuPPh}_{3}\right](1 \mathrm{~b})$ and $\left[\left(p-\mathrm{CF}_{3}-\mathrm{C}_{6} \mathrm{H}_{4}\right) \mathrm{AuPPh}_{3}\right](\mathbf{1 c}) .{ }^{[17]}$ Since the averaged signals reflect the weighted average of the mono- and digold aryl chemical shifts, it thus provided the means to determine the equilibrium position as a function of structure and reaction variables. This technique was used to measure how counterions and aryl electronic effects influenced the propensity for digold formation. 
When 1 equiv of different $\left[\mathrm{Ph}_{3} \mathrm{PAu}\right] \mathrm{Y}$ complexes were added to a solution of [(4-MeO$\left.\mathrm{C}_{6} \mathrm{H}_{4}\right) \mathrm{AuPPh}_{3}$ ] (1a), averaged 4-anisyl signals were observed by ${ }^{1} \mathrm{H}$ NMR spectroscopy. The average percentage of $1 \mathbf{a}$ bound as digold was calculated from the measured chemical shifts of the two inequivalent aromatic hydrogen atoms and the methoxy group, and the correlations in Figure 1 with the explicit assumption that the time averaged 4-anisyl shifts in the digold were not sensitive to $\mathrm{Y}^{-}$.

In the case of $\mathrm{Y}=\mathrm{OAc}$ and $\mathrm{OBz}$, added quantities of $\left[\mathrm{Ph}_{3} \mathrm{PAu}\right] \mathrm{Y}$ to $1 \mathrm{a}$ caused no shifting in the anisyl peaks, suggesting that no digold was formed under these conditions (Table 1). With less binding counterions shifting was observed, allowing equilibrium concentrations of digold to be calculated. In these cases, OONB (ortho-nitrobenzoate) provided $1 \pm 1 \%$ digold, $12 \pm 2 \%$ with OPNB (para-nitro-benzoate), and $41 \pm 1 \%$ and $88 \pm 1 \%$ digold for TFA (trifluoroacetate) and OTs (tosylate), respectively. Complete conversion to the digold form was calculated for the least coordinating $\mathrm{NTf}_{2}$ (bistriflimide). This trend was reasonably rationalized by the $\mathrm{p} K_{\mathrm{a}}$ of the conjugate acids (with the exception of OONB), and suggested that it was strong ion pairing in $\left[\mathrm{Ph}_{3} \mathrm{PAu}\right] \mathrm{Y}$ that inhibited digold formation for the more binding anions. As shown in the final two columns of Table 1, the affinity of $\left[\mathrm{Ph}_{3} \mathrm{PAu}\right] \mathrm{Y}$ to $\mathbf{1 b}$ and $\mathbf{1 c}$ was considerably lower for the less electron-rich aryl ligands, with significant quantities of digold only being observed for the least coordinating anions. This trend supports the notion that the $\mathrm{Au}_{2} \mathrm{C}$ three-center-two-electron interaction is electrondeficient, and competes with the counterion.

To determine how the ratio of mono- and digold was affected by concentration, aliquots of $\mathrm{CD}_{2} \mathrm{Cl}_{2}$ were added to a 1:1 mixture of $\mathbf{1 a}$ and $\left[\mathrm{Ph}_{3} \mathrm{PAu}\right] \mathrm{OTs}{ }^{[18]}$ As the component concentration was decreased 4.6-fold the percentage of 1a bound as digold only decreased from $89.2 \%$ to $87.5 \%$, which was more muted than expected for a $2: 1$ stoichiometry, and likely reflects the diminished ion pairing in the more charge-dispersed digold aryl complex compensating for the stoichiometry. In the context of catalysis, this observation suggests that digold formation is not heavily penalized at low catalyst loadings.

With this increased understanding of digold formation, we attempted to study its competing, but essential product yielding step, protodemetalation. To understand this process independent of digold formation the reaction of $1 \mathbf{a}$ with 4 equiv of $\mathrm{AcOH}$ was monitored by ${ }^{1} \mathrm{H}$ NMR spectroscopy. Based on data in Table 1 we expected that these conditions would avoid the presence of digold, which should inhibit protodemetalation. Acetic acid was chosen because it enabled pseudo-first order reaction conditions to be established. ${ }^{[19]}$ As expected, a smooth conversion of $\mathbf{1 a}$ to $\mathbf{4 a}$ and $\left[\mathrm{Ph}_{3} \mathrm{PAu}\right] \mathrm{OAc}$ was observed. Unexpected, however, was a steady downfield movement of the 4-anisyl resonances of $\mathbf{1 a}$ as the protodemetallation progressed (Figure 2, $)^{[20]}$ An even larger shift to digold was detected in the reaction of 1a and 10 equiv of $\mathrm{AcOH} .{ }^{[21]}$ Although this observation suggested that digold was being formed during the protodemetalation with $\mathrm{AcOH}$, no digold was detected on mixing $1 \mathrm{a}$ and $\left[\mathrm{Ph}_{3} \mathrm{PAu}\right] \mathrm{OAc}$ in the absence of $\mathrm{AcOH}$ (entry 1, Table 1). To probe whether the Dd was due to a build-up of $\left[\mathrm{Ph}_{3} \mathrm{PAu}\right] \mathrm{OAc}$, the reaction was repeated in the presence of 1 equiv of $\left[\mathrm{Ph}_{3} \mathrm{PAu}\right] \mathrm{OAc}$. As shown in Figure $2(\mathbf{O})$, a near doubling in equilibrium digold was observed.

This behavior suggested that under these reaction conditions, acetate anion was effectively less coordinating. The data suggests that an acid/base interaction between $\mathrm{AcOH}$ and $\left[\mathrm{R}_{3} \mathrm{PAu}\right] \mathrm{OAc}$ [Eq. (3)] creates a homoconjugate acid/base pair which causes the acetate to become less coordinating. ${ }^{[22]}$ Since the amount of digold was highly sensitive to the donor properties of the counterion (Table 1), such an interaction could reduce the degree of contact ion pairing. ${ }^{[23]}$ Titration of $\mathrm{AcOH}$ into $\left[\mathrm{Ph}_{3} \mathrm{PAu}\right] \mathrm{OAc}$, however, lead to only a tiny shift in the phosphine resonance in the ${ }^{31} \mathrm{P}$ NMR spectrum, suggesting that the thermodynamic 
effect was small, though the kinetic effect could be larger. Similar experiments with alternative counterions confirmed the generality of the observation as all cases $(\mathrm{Y}=\mathrm{OBz}$, OPNB, OONB, TFA, and OTs) led to significant downfield shifts consistent with an increase in digold formation. ${ }^{[24]}$<smiles></smiles>

When the kinetics of protodemetalation for these latter experiments was determined, it became clear that the gold salts also affected the rate of this key catalytic step. As shown in Table 2, the effect of added $\left[\mathrm{Ph}_{3} \mathrm{PAu}\right] \mathrm{Y}$ on the kinetics for protodemetalation of $\mathbf{1 a}$ by $\mathrm{AcOH}$ depended non-linearly with the coordinating character of the anion. At the extreme of non-coordination, $\mathrm{Y}=\mathrm{NTf}_{2}$, a very low rate was expected, as the digold does not react with $\mathrm{AcOH} .{ }^{[4]}$ The increase in rate at intermediate donating ability, however, was unexpected and will require further study.

Our studies have thus established, by using $\left[\mathrm{Ph}_{3} \mathrm{PAuAr}\right]$ complexes as models for catalytic gold vinyl intermediates, a number of important reactivity principles of relevance to catalytic activity and speciation. 1) electron-rich aryl (and thus vinyl) ligands have a heightened propensity to form less reactive digold structures, 2) digold formation is more favorable for the less coordinating counterions (which is also influenced by Brønsted acids), and 3) exogenous gold salts can affect the rate of fundamental processes like protodemetalation even though they do not appear in the balanced equation. Each of these scenarios are commonly encountered in gold(I) catalysis. For example, point (1) explains why the isolable electron-deficient Hammond vinyl rests (and is isolated) in a monomeric form, ${ }^{[25]}$ while the gold vinyl generated by the hydroarylation of allenes rests (and is isolated) in the digold form. These results additionally illuminate on the challenges of developing highly efficient multi-step catalysts. To maximize substrate activation, one typically aims for the least coordinating anions, and while this almost certainly maximizes the initiation step of a catalytic cycle, point (2) demonstrates that these more activated $[\mathrm{LAu}]^{+}$ions are also more apt to intercept gold vinyl intermediates and generate more stable, less reactive, digold intermediates (e.g. for protodemetalation). The results reported herein help provide a rationale for the inevitable search for catalysts that balance the competing demands of efficiently circumnavigating a catalytic cycle.

\section{Experimental Section}

Reaction conditions were chosen to mimic concentrations and temperatures commonly used in gold(I) catalysis. See the Supporting Information for details.

\section{Supplementary Material}

Refer to Web version on PubMed Central for supplementary material.

\section{References}

1. a) Krause N, Winter C. Chem. Rev. 2011; 111:1994-2009. [PubMed: 21314182] b) Corma A, Leyva-Pérez A, Sabater MJ. Chem. Rev. 2011; 111:1657-1712. [PubMed: 21391565] c) Boorman TC, Larrosa I. Chem. Soc. Rev. 2011; 40:1910-1925. [PubMed: 21103517] d) Aubert C, Fensterbank L, Garcia P, Malacria M, Simonneau A. Chem. Rev. 2011; 111:1954-1993. [PubMed: 21391568] e) Bandini M. Chem. Soc. Rev. 2011; 40:1358-1367. [PubMed: 21103507] f) Pradal A, 
Toullec PY, Michelet V. Synthesis. 2011:1501-1514.g) Rudolph M, Hashmi ASK. Chem. Commun. 2011; 47:6536-6544.h) Sengupta S, Shi X. ChemCatChem. 2010; 2:609-619.i) Fürstner A. Chem. Soc. Rev. 2009; 38:3208-3221. [PubMed: 19847352] j) Li Z, Brouwer C, He C. Chem. Rev. 2008; 108:3239-3265. [PubMed: 18613729] k) Widenhoefer RA. Chem. Eur. J. 2008; 14:5382-5391. [PubMed: 18442031] 1) Hashmi ASK, Rudolph M. Chem. Soc. Rev. 2008; 37:1766-1775. [PubMed: 18762826] m) Gorin DJ, Sherry BD, Toste FD. Chem. Rev. 2008; 108:3351-3378. [PubMed: 18652511] n) Jiménez-Núñez E, Echavarren AM. Chem. Rev. 2008; 108:3326-3350. [PubMed: 18636778] o) Arcadi A. Chem. Rev. 2008; 108:3266-3325. [PubMed: 18651778] p) Hashmi ASK. Chem. Rev. 2007; 107:3180-3211. [PubMed: 17580975] q) Gorin DJ, Toste FD. Nature. 2007; 446:395-403. [PubMed: 17377576] r) Hashmi ASK, Hutchings GJ. Angew. Chem. 2006; 118:8064-8105.Angew. Chem. Int. Ed. 2006; 45:7896-7936.s) Fürstner A, Davies PW. Angew. Chem. 2007; 119:3478-3519.Angew. Chem. Int. Ed. 2007; 46:3410-3449.

2. The isolation of gold intermediates and model complexes has been reviewed: Hashmi ASK. Angew. Chem. 2010; 122:5360-5369. Angew. Chem. Int. Ed. 2010; 49:5232-5241. Raubenheimer HG, Schmidbaur H. S. Afr. J. Sci. 2011; 107(3-4):1-13. Hashmi ASK. Gold Bull. 2009; 42:275-279. Schmidbaur H, Schier A. Organometallics. 2010; 29:2-23.

3. Most often $\mathrm{E}^{+}$is a proton (see ref. [25]), but halonium ions and metal electrophiles were also used, see: Wegner HA, Auzias M. Angew. Chem. 2011; 123:8386-8397. Angew. Chem. Int. Ed. 2011; 50:8236-8247. Hirner JJ, Shi Y, Blum SA. Acc. Chem. Res. 2011; 44:603-613. [PubMed: 21644576], and references therein. Model complexes were used to understand $\mathrm{E}^{+}$reactivity better. For selected examples, see: Mankad NP, Toste FD. J. Am. Chem. Soc. 2010; 132:12859-12861. [PubMed: 20726525] Hashmi ASK, Ramamurthi TD, Rominger F. J. Organomet. Chem. 2009; 694:592-597. Hashmi ASK, Ramamurthi TD, Todd MH, Tsang AS-K, Graf K. Aust. J. Chem. 2010; 63:1619-1626. Weber D, Gagné MR. Chem. Commun. 2011; 47:5172-5174.

4. a) Weber D, Tarselli MA, Gagné MR. Angew. Chem. 2009; 121:5843-5846.Angew. Chem. Int. Ed. 2009; 48:5733-5736.b) Weber D, Gagné MR. Org. Lett. 2009; 11:4962-4965. [PubMed: 19807117]

5. a) Schmidbaur H, Schier A. Chem. Soc. Rev. 2008; 37:1931-1951. [PubMed: 18762840] b) Schmidbaur H. Gold Bull. 2000; 33:1-10.c) Schmidbaur H. Chem. Soc. Rev. 1995; 24:391-400.

6. Seidel G, Lehmann CW, Fürstner A. Angew. Chem. 2010; 122:8644-8648. Angew. Chem. Int. Ed. 2010; 49:8466-8470. Porter KA, Schier A, Schmidbaur H. Organometallics. 2003; 22:4922-4927. Nesmeyanov AN, Perevalova EG, Grandberg KI, Lemenovskii DA. Izv. Akad. Nauk SSSR Ser. Khim. 1974; 5:1124-1137. Osawa M, Hoshino M, Hashizume D. Dalton Trans. 2008:2248-2252. [PubMed: 18414748] Usón R, Laguna A, Fernandez EJ, Media A, Jones PG. J. Organomet. Chem. 1988; 350:129-138. Schmidbaur H, Inoguchi Y. Chem. Ber. 1980; 113:1646-1653. Alcarazo M, Lehmann CW, Anoop A, Thiel W, Fürstner A. Nat. Chem. 2009; 1:295-301. [PubMed: 21378871] Vicente J, Singhal AR, Jones PG. Organometallics. 2002; 21:5887-5900. see also ref. [10].

7. a) Raubenheimer HG, Schmidbaur H. Organometallics. 2011b) Hoffmann R. Angew. Chem. 1982; 94:725-739.Angew. Chem. Int. Ed. Engl. 1982; 21:711-724.

8 . We have attempted the synthesis of non-heteroatom and noncyclopropyl-stabilized digold vinyl complexes, but these complexes rapidly decomposed through $\mathrm{C}-\mathrm{C}$ bond forming homocoupling as published by Fürstner et al. (ref. [6a]). The same reactivity was also observed with aryl complexes, but at a much lower rate. Electron-deficient digold aryl complexes (e.g. 1c) decomposed at a significantly higher rate than electron-rich digold aryl complexes (e.g. 1a).

9. For a complete list of synthesized mononuclear and dinuclear gold aryl complexes, see the Supporting Information.

10. a) Grandberg KI, Dyadchenko VP. J. Organomet. Chem. 1994; 474:1-24.b) Grandberg KI. Russ. Chem. Rev. 1982; 51:249-262.

11. Croix C, Balland-Longeau A, Allouchi H, Giorgi M, Duchêne A, Thibonnet J. J. Organomet. Chem. 2005; 690:4835-4843.

12. CDCC $851149\left(\left[\left(2,5-\left(\mathrm{OCH}_{3}\right)_{2}-\mathrm{C}_{6} \mathrm{H}_{3}\right) \mathrm{AuPPh}_{3}\right]\right)$ and $851150\left(\left[\left(3-\mathrm{CH}_{3}-\mathrm{C}_{6} \mathrm{H}_{4}\right) \mathrm{AuPPh}_{3}\right]\right)$ contain the supplementary crystallographic data. These data can be obtained free of charge from The Cambridge Crystallographic Data Centre via www.ccdc.cam.ac. uk/data_request/cif.

13. Mézailles N, Ricard L, Gagosz F. Org. Lett. 2005; 7:4133-4136. [PubMed: 16146370] for a review on silver-free gold catalysts, see: Schmidbaur H, Schier A. Z. Naturforsch. B. 2011; 66:329-350. 
14. CCDC $851147\left(\left[\left(2,5-\left(\mathrm{OCH}_{3}\right)_{2}-\mathrm{C}_{6} \mathrm{H}_{3}\right)\left(\mathrm{AuPPh}_{3}\right)_{2}\right] \mathrm{NTf}_{2}\right)$ and $851148\left(\left[\left(2-\mathrm{CH}_{3}-\mathrm{C}_{6} \mathrm{H}_{4}\right)\right.\right.$ $\left.\left(\mathrm{AuPPh}_{3}\right)_{2} \mathrm{NTf}_{2}\right)$ contain the supplementary crystallographic data. These data can be obtained free of charge from The Cambridge Crystallographic Data Centre via www.ccdc.cam.ac.uk/data_request/cif.

15. Nesmeyanov AN, Perevalova EG, Grandberg KI, Lemenovskii DA, Baukova TV, Afanassova OB. J. Organomet. Chem. 1974; 65:131-144.

16. The formation of a trigold species was previously reported: Rakhimov RD, Butin KP, Grandberg KI. J. Organomet. Chem. 1994; 464:253-260.

17. See the Supporting Information for details.

18. Concentration of both reagents was $0004 \mathrm{~m}$; see the Supporting Information for details.

19. Protodemetalation of 1 c could not be performed due to overlapping aryl and $\mathrm{PPh}_{3}$ signals in the ${ }^{1} \mathrm{H}$ NMR spectrum.

20. A slight downfield shift indicating digold formation was also observed during the protodemetalation of $\mathbf{1 b}$, but was less pronounced than with $\mathbf{1 a}$.

21. See the Supporting Information for reaction conditions and tables.

22. An activation of a Brønsted acid by a gold Lewis acid was recently reported: Kanno O, Kuriyama W, Wang ZJ, Toste FD. Angew. Chem. 2011; 123:10093-10096. Angew. Chem. Int. Ed. 2011; 50:9919-9922.

23. Koh JH, Larsen AO, Gagné MR. Org. Lett. 2001; 3:1233-1236. [PubMed: 11348202]

24. See the Supporting Information for details.

25. Blum has demonstrated that the Hammond vinyl was not kinetically basic in comparison to [Ph $\left.{ }_{3} \mathrm{PAuPh}\right]$, see: Roth KE, Blum SA. Organometallics. 2010; 29:1712-1716. Liu L-P, Xu B, Mashuta MS, Hammond GB. J. Am. Chem. Soc. 2008; 130:17642-17643. [PubMed: 19055329] in the reaction of gold complexes with protons $\mathrm{H}_{2} \mathrm{O}$ molecules play a crucial role as proton shuttles, see: Krauter CM, Hashmi ASK, Pernpointner M. ChemCatChem. 2010; 2:1226-1230. 

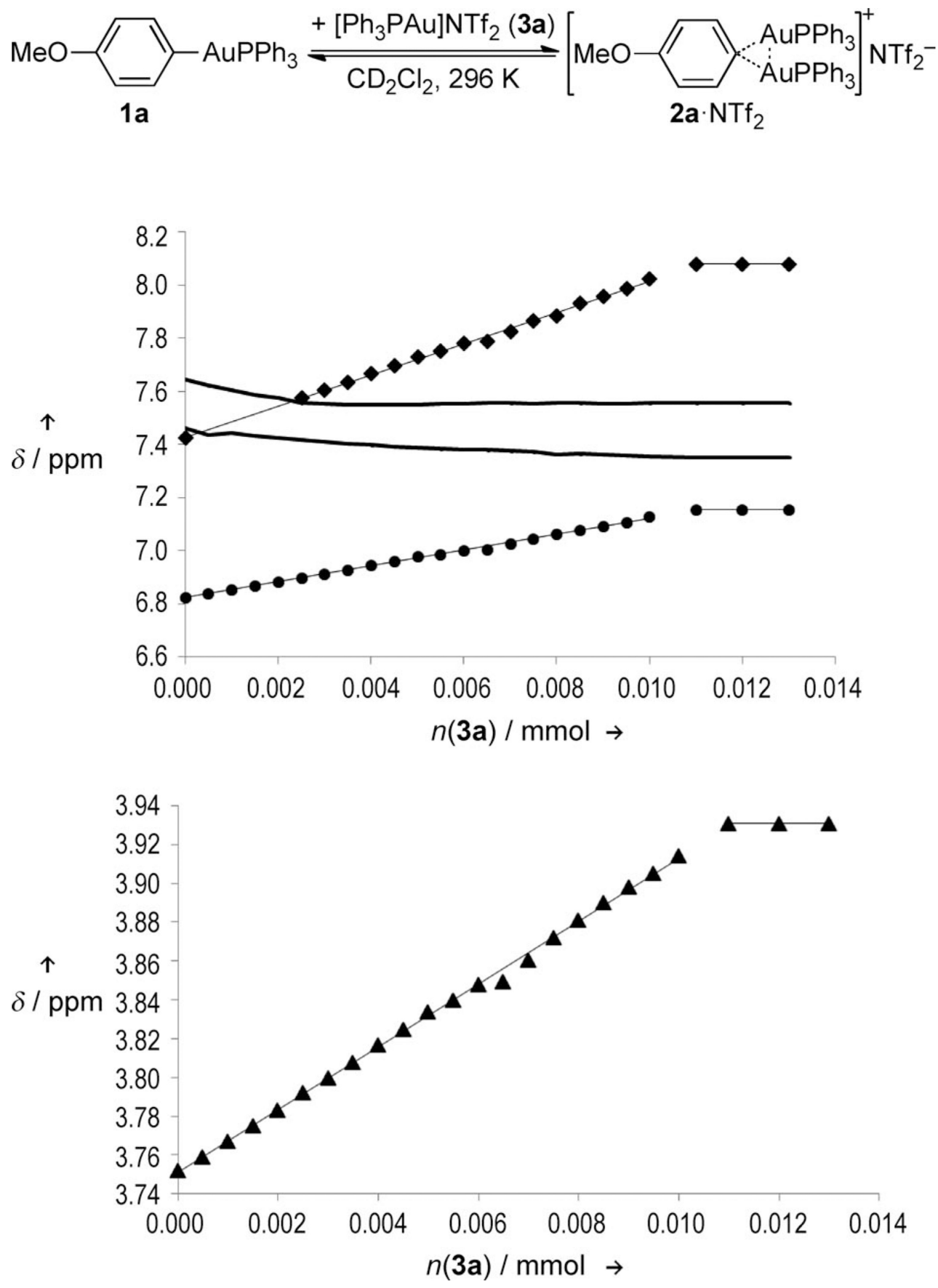

Figure 1.

Addition of aliquots of 3a to a solution of 1a caused a linear downfield shifting of the timeaveraged ${ }^{1} \mathrm{H}$ signals of $\mathbf{1 a}$ and $\mathbf{2 a} \cdot \mathrm{NTf}_{2}$. Upper diagram: $\bullet$ ortho- $\mathrm{H}(y=58.686 x+7.428$, $\left.R^{2}=0.998\right), \bigcirc$ meta $-\mathrm{H}\left(y=29.727 x+6.824, R^{2}=0.998\right),-\mathrm{PPh}_{3}$; lower diagram: para-OMe $\left(y=16.156 x+3.751, R^{2}=0.999\right)$. 

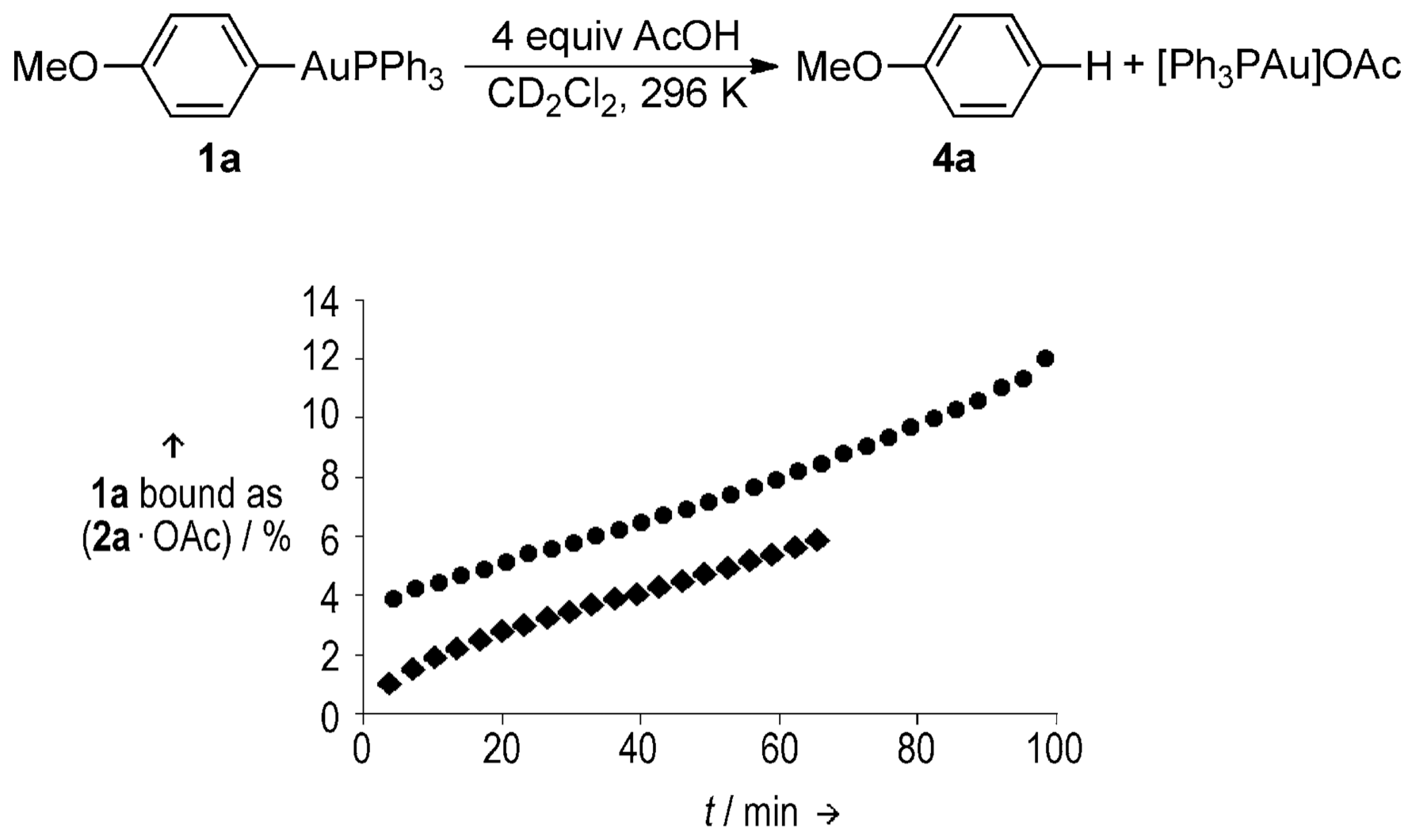

Figure 2.

Growth in calculated percentage of 1a bound as digold 2a.OAc over the course of the protodemetalation of $\mathbf{1 a}$ with 4 equiv of $\mathrm{AcOH}(\bullet)$. The round data points $(\bullet)$ correspond to the experiment with an additional equivalent of $\left[\mathrm{Ph}_{3} \mathrm{PAu}\right] \mathrm{OAc}$. 
Schmidbaur

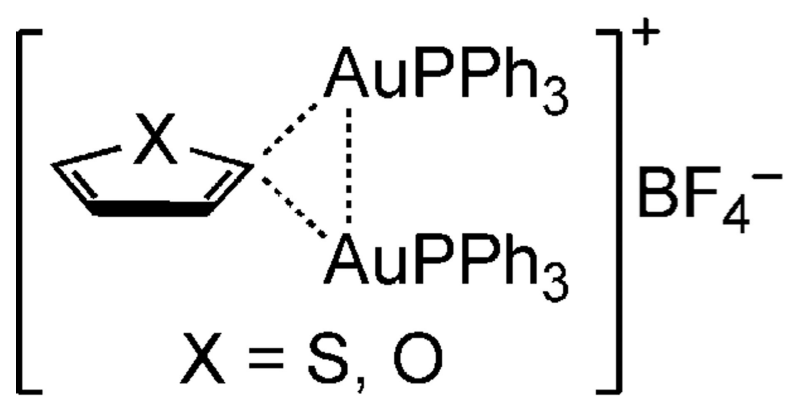

Grandberg

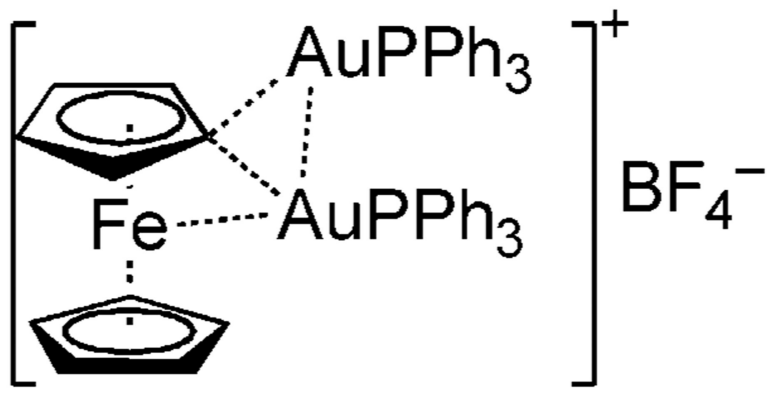

\section{Fürstner}

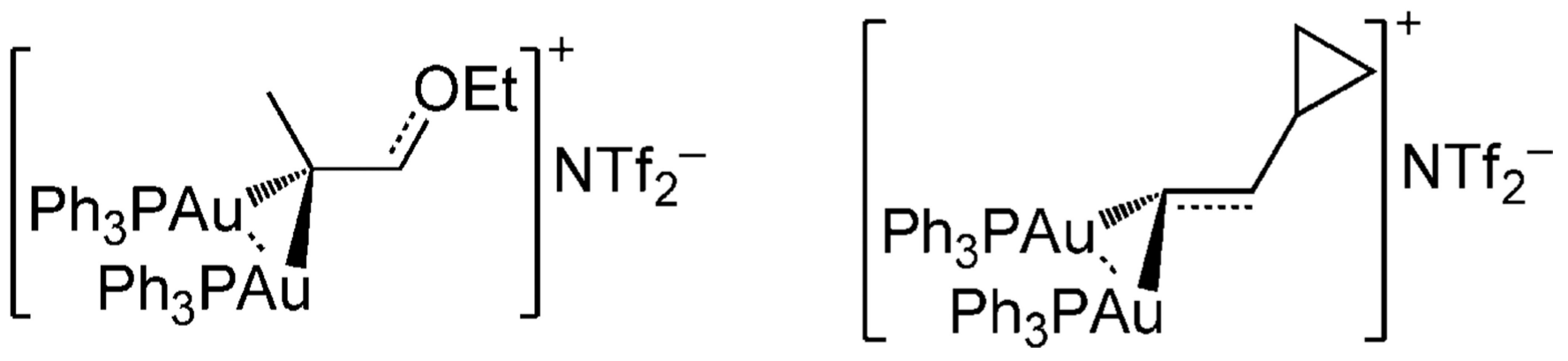

Scheme 1.

Selected examples of digold-aryl and digold-vinyl complexes. 


\section{Table 1}

Digold equilibrium percentages determined by the averaged proton signal method as a function of counterion and aryl ligand.

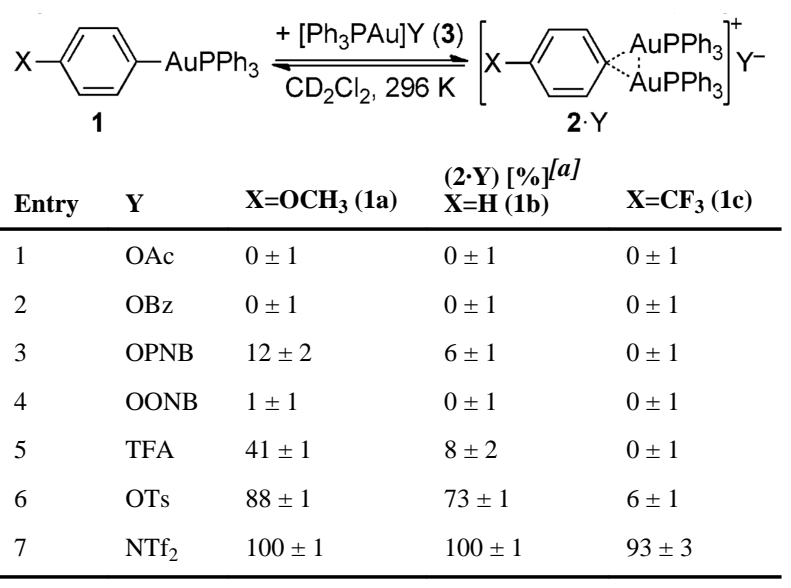

${ }^{[a]}$ Determined by averaged ${ }^{1} \mathrm{H}$ NMR signals of $0.1 \mathrm{~mL}$ of $\mathbf{1}(0.01 \mathrm{~m}), 0.1 \mathrm{~mL}$ of $3(0.01 \mathrm{~m}), 0.3 \mathrm{~mL}$ of $\mathrm{CD}_{2} \mathrm{Cl}_{2}$. 
Table 2

Rate of protodemetalation of $\mathbf{1 a}$ with $\mathrm{AcOH}$ in the presence of different $\left[\mathrm{Ph}_{3} \mathrm{PAu}\right] \mathrm{Y}(\mathbf{3})$ complexes.

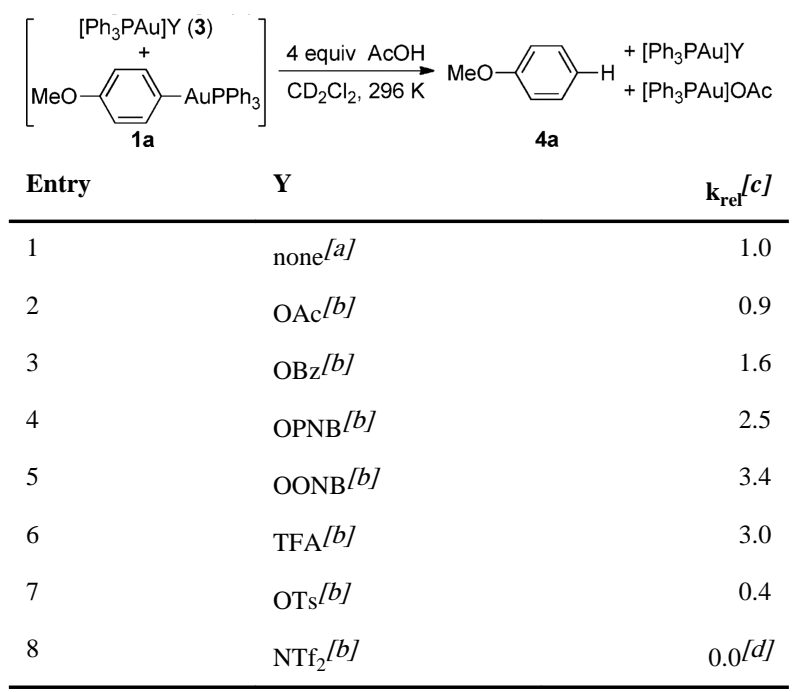

${ }^{[a]} 0.1 \mathrm{~mL}$ of $1 \mathbf{a}(0.01 \mathrm{~m}), 0.1 \mathrm{~mL}$ of $\mathrm{CD}_{2} \mathrm{Cl}_{2}, 0.1 \mathrm{~mL}$ of internal standard mesitylene $(0.025 \mathrm{~m}), 0.2 \mathrm{~mL}$ of $\mathrm{AcOH}(0.02 \mathrm{M})$.

${ }^{[b]} 0.1 \mathrm{~mL}$ of $1 \mathbf{a}(0.01 \mathrm{M}), 0.1 \mathrm{~mL}$ of $3(0.01 \mathrm{~m}), 0.1 \mathrm{~mL}$ of internal standard mesitylene (0.025 M), $0.2 \mathrm{~mL}$ of AcOH $(0.02 \mathrm{M})$.

${ }^{[c]}$ For determination of $k_{\text {rel }}$ see the Supporting Information.

${ }^{[d]}$ In this reaction, all of 1a was bound as digold and no conversion to $4 \mathbf{a}$ was observed for $1 \mathrm{~h}$. 